
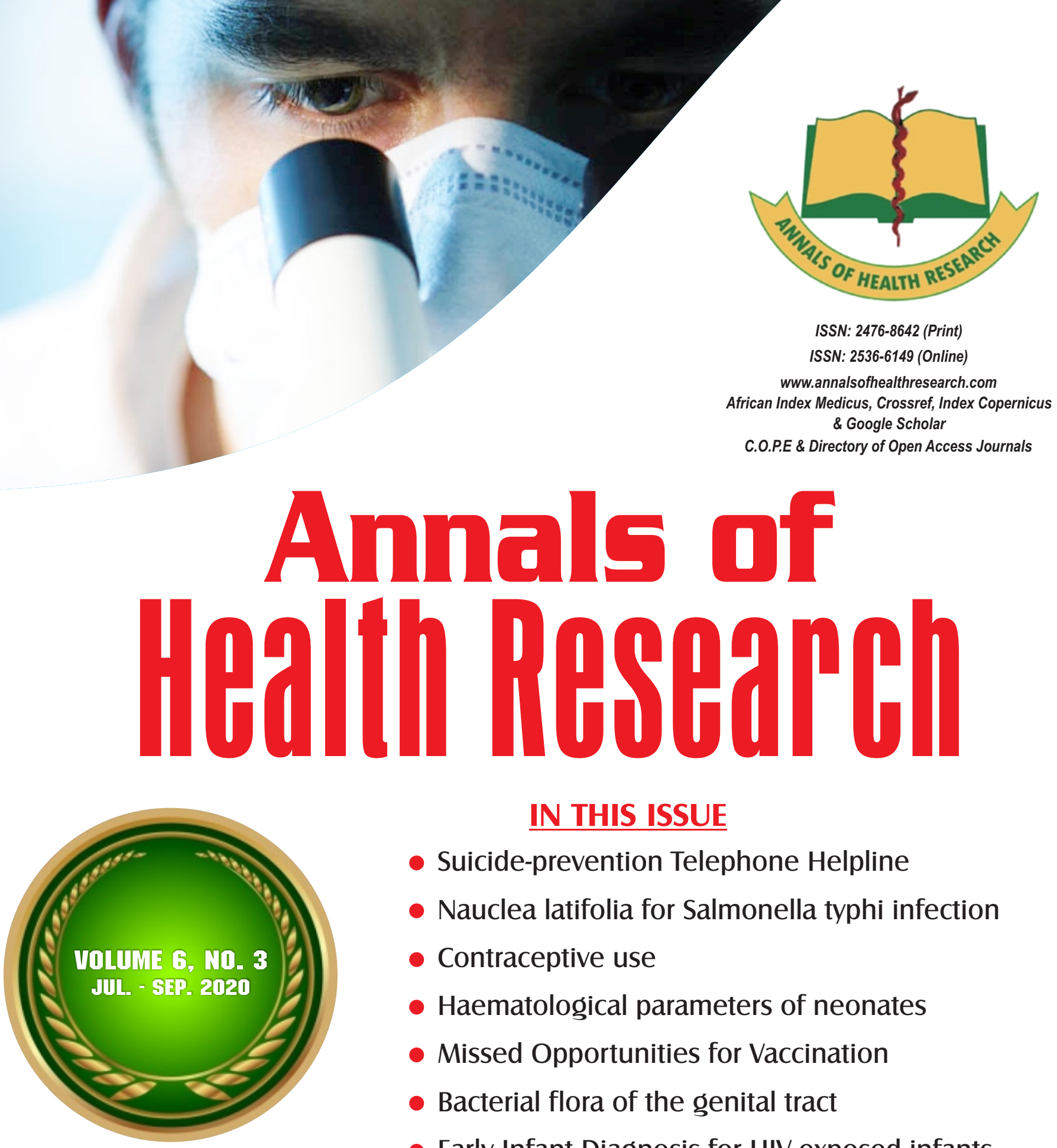

IN THIS ISSUE

- Suicide-prevention Telephone Helpline

- Nauclea latifolia for Salmonella typhi infection

- Contraceptive use

- Haematological parameters of neonates

- Missed Opportunities for Vaccination

- Bacterial flora of the genital tract

- Early Infant Diagnosis for HIV-exposed infants

- Bone markers and cardiovascular risk factors

- Attitude to termination of pregnancies

- Herpes zoster ophthalmicus

- Neonatal hyperinsulinaemic hypoglycaemia

- Paediatric perineal injury

PUBLISHED BY THE MEDICAL

AND DENTAL CONSULTANTS ASSOCIATION

OF NIGERIA, OOUTH, SAGAMU, NIGERIA.

www.mdcan.oouth.org.ng 


\title{
The attitude of Nigerian women to termination of pregnancies with major congenital anomalies Enabudoso EJ ${ }^{1}$, Akinmoladun JA ${ }^{2}$
}

${ }^{1}$ Department of Obstetrics and Gynaecology, University of Benin Teaching Hospital, Benin-City, Edo State, Nigeria

${ }^{2}$ Department of Radiology, College of Medicine, University of Ibadan, Ibadan, Oyo State, Nigeria

*Correspondence: Dr JA Akinmoladun, Department of Radiology, College of Medicine, University of Ibadan, Ibadan, Oyo State, Nigeria. E-mail: jaakinmoladun@yahoo.com; ORCID - https://orcid.org/0000-0002-3294-5530.

\begin{abstract}
Background: When couples are confronted with a pregnancy in which there is a major foetal anomaly, they have only two options: termination of the pregnancy or allowing the baby to be born.

Objective: To determine the attitude of pregnant women in Nigeria to termination of pregnancies with major congenital anomalies.

Methods: This is a descriptive study undertaken at two centres in Nigeria. Structured and pretested selfadministered questionnaire was used for data collection including socio-demographics and attitude to termination of pregnancies with major congenital anomalies.

Results: Three hundred and fifty-six pregnant women participated in the study. Most of the respondents were in the 21-40 years age group. More than half of the participants $(236 ; 66.3 \%)$ agreed with the termination of pregnancies with major congenital anomalies and some of their reasons were "to prevent the baby from suffering" and "to prevent waste of resources". For the 120 (33.7\%) who did not agree with termination of such pregnancies, some of their reasons were "to trust God for a miracle" and "hoping that God will not allow such" Conclusion: The findings from this study show that majority of the women were favourably disposed to the termination of pregnancies with major anomalies. However, women with such pregnancies need to be adequately counselled to be aware of the consequences of the decisions they make. Also, in a country where there are legal restrictions of abortion, efforts should be made to consider termination of pregnancies with major anomalies in the abortion laws.
\end{abstract}

Keywords: Abortion, Foetus, Major congenital anomalies, Nigeria, Termination of pregnancy, Ultrasound.

\section{Introduction}

Congenital anomalies (CAs) are major causes of death in both the developed and developing countries of the world. ${ }^{[1,2]}$ A majority of these deaths occur during the first year of life and thus, contribute mostly to high infant mortality rate. [3] Congenital anomalies can contribute to long-term disability, which may have significant impacts on individuals, families, health-care systems, and the larger society. [3] Christianson et al. estimated 7.4 million infants are born each year with a major birth defect, of which $94 \%$ occur in middle and low-income countries. [4]

Survivors with congenital anomalies usually require frequent hospital visits as a result of 
their anomalies or associated complications. [5] These visits may result in hospitalisations, which account for $15 \%$ to $30 \%$ of all paediatric hospitalisations with estimated higher cost compared to other causes of hospitalisation. [5] In addition to the mortality and morbidity burden of congenital malformations, they have a major socio-economic impact on the affected families as well as the community as a whole. $[5,6]$

The availability of prenatal ultrasound screening permits the precise diagnosis of a range of foetal abnormalities, including those incompatible with life. ${ }^{[6]}$ The detection rate depends on the expertise of the sonologist/sonographer and in the hand of a specialist, detection rates can range from 80 to $95 \%$. [7,8] When couples are confronted with a pregnancy in which there is a major foetal anomaly, they have only two options: termination of the pregnancy or allowing the baby to be born, after which the baby may die within a short space of time or live with long term major disabilities. ${ }^{[8]}$

In most developed countries of the world, abortion due to foetal anomalies is legal. [9,10] For example, in England, Wales and Scotland, Termination of Pregnancy for Foetal Anomaly (TOPFA) is legal under the Abortion Act 1967, with no upper gestational limit. [9] In South Africa, a middle-income country, termination of pregnancy is performed at any period of gestation if it is agreed by consensus decision that continuation of the pregnancy will result in a severely handicapped child. [11] However, abortion laws are significantly more restrictive in most low-income countries, including Nigeria, where abortion is allowed only to save the mother's life. [12] It is also often permitted on the grounds of lethal foetal anomalies in some of these other countries. $[10,12]$

This study aimed at determining the attitude of pregnant women in Nigeria to termination of pregnancies with major congenital anomalies.

\section{Methods}

This descriptive study was carried out from January to June 2018 at two centres in Nigeria: antenatal clinics of the University of Benin Teaching Hospital Complex, Benin-City and University College Hospital, Ibadan. Three hundred and fifty-six consenting pregnant women that were referred for an obstetric ultrasound during this period were included in the study irrespective of their socioeconomic, religious or literary background. Those who denied consent for the study were excluded.

\section{Ethical considerations}

This study was approved by the University of Ibadan /University College Hospital, Ibadan Joint Research Ethics Committee. The benefit of the study was explained and informed verbal consent was taken before the administration of the questionnaire.

\section{Data collection}

A structured, pretested questionnaire containing questions regarding demographics, knowledge about congenital anomalies and attitude to termination of a pregnancy with major congenital anomalies, was used for the study. Before filling the questionnaires, the subjects were informed about the objectives of the study and the meaning of major congenital abnormalities were explained to them with examples.

Major congenital anomalies were explained as birth defects that will reduce the life expectancy of the child and these may be severe or lethal. Severe anomalies are those that require medical or surgical intervention after the baby is born while the lethal ones are those defects that will result in either stillbirth or early infant death. [13] 
The self-administered questionnaires were distributed to all the women that agreed to participate in the study. The questionnaire was divided into two sections: Section A was on the socio-demographics of the participants while section B was on their attitude to termination of pregnancies with major anomalies. In this latter section, participants were given an option of either 'yes' or 'no' to termination of pregnancies with major anomalies and were requested to give reasons for their choices. The frequencies of the various reasons were collated for analysis.

\section{Data analysis}

The data generated were analysed using the Statistical Package for Social Sciences (SPSS) software version 20 for Windows (SPSS Inc. Chicago, IL, USA.). Frequency tables and percentages were used to present the results of the socio-demographic characteristics and ChiSquare test was used to compare proportions with the level of statistical significance set at $p$ less than 0.05 .

\section{Results}

Three hundred and fifty-six (356) participants filled the questionnaire during the study period. Most of the participants were in the 2130 years and 31- 40 years age groups which accounted for $48.0 \%$ and $48.9 \%$ of the respondents respectively. Only 7 (2.0\%) belonged to the 41 to 50 years age group. Two hundred and ninety-six (82.5\%) had tertiary education, while $6(1.8 \%)$ had no formal education. Most of the women (344; 96.6\%) were married with only $12(3.4 \%)$ being single. More than half of the participants $(226 ; 63.4 \%)$ belonged to the Pentecostal Christian denominations while $10(2.8 \%)$ were Jehovah witnesses and $23(6.5 \%)$ were Muslims.

More than half of the participants $(236 ; 66.3 \%)$ agreed with the termination of pregnancies with major congenital anomalies while 33.7\% disagreed (Table I). There was no statistically significant association between the choices of agreement or disagreement with the different socio-demographic characteristics of the women. It was observed that $66.7 \%, 66.7 \%$ and $57.0 \%$ of the women in the $21-30,31-40$ and $>40$ years age groups respectively agreed with the termination of pregnancies with major anomalies. Also, 8 (66.7\%) and $228(66.3 \%)$ of the single and married mothers respectively were willing to terminate such pregnancies. Most of the women in the various religions/ denominations agreed with the termination of such pregnancies apart from Jehovah witnesses among whom only $4(40 \%)$ agreed with the termination of such pregnancies (Table I).

As shown in Table II, various reasons were given by the participants who agreed with the termination of a pregnancy with major congenital anomalies. Majority of the women believed it was "to prevent the baby from suffering" (25.4\%); this was followed by those who "...don't want to waste resources" (8.5\%) and those who would do it "to prevent recurrent visits to the hospital" (5.9\%). Very few of the women gave their reasons as "I do not want a repeat from previous pregnancy" $(1.7 \%)$ and "to prevent future depression for the baby" (1.3\%).

Different reasons were given by the participants who disagreed with the termination of pregnancies with major congenital anomaly as shown in Table III. Majority of the women were going to "trust God for a miracle" $(46.7 \%)$; this was followed by those who ".....felt they will be committing murder" $(13.3 \%)$. Very few believed that "the baby has the right to live" (8.3\%), "God will not allow it" $(6.7 \%)$ and "....will be too attached to the baby" $(3.3 \%)$. 
Table I: Relationship between socio-demographic characteristics and attitude of pregnant women to termination of pregnancy with major congenital anomalies.

\begin{tabular}{|c|c|c|c|c|}
\hline \multirow[t]{2}{*}{ Characteristics } & \multicolumn{3}{|c|}{ Attitude } & \multirow[t]{2}{*}{$\overline{p \text {-value }}$} \\
\hline & Agreed (\%) & Disagreed (\%) & Total & \\
\hline \multicolumn{5}{|l|}{ Age Group (Years) } \\
\hline$<20$ & $2(50.0)$ & $2(50.0)$ & 4 & 0.859 \\
\hline $21-30$ & $114(66.7)$ & $57(33.3)$ & 171 & \\
\hline $31-40$ & $116(66.7)$ & $58(33.3)$ & 174 & \\
\hline$>40$ & $4(57.1)$ & $3(42.9)$ & 7 & \\
\hline \multicolumn{5}{|l|}{ Marital Status } \\
\hline Single & $8(66.7)$ & $4(33.3)$ & 12 & 0.958 \\
\hline Married & $228(66.3)$ & $116(33.7)$ & 344 & \\
\hline \multicolumn{5}{|l|}{ Religion/Denomination } \\
\hline Catholic & $43(74.1)$ & $15(25.9)$ & 58 & 0.127 \\
\hline Protestant & $15(48.4)$ & $16(51.6)$ & 31 & \\
\hline Pentecostal & $153(67.7)$ & $73(32.3)$ & 226 & \\
\hline Jehovah's witness & $4(40.0)$ & $6(60.0)$ & 10 & \\
\hline Islam & $15(65.2)$ & $8(34.8)$ & 23 & \\
\hline Others & $6(75.0)$ & $2(25.0)$ & 8 & \\
\hline \multicolumn{5}{|c|}{ Educational qualification } \\
\hline No formal education & $3(50.0)$ & $3(50.0)$ & 6 & 0.753 \\
\hline Primary & $8(72.7)$ & $3(27.3)$ & 11 & \\
\hline Secondary & $27(62.8)$ & $16(37.2)$ & 43 & \\
\hline Tertiary & 198 (66.9) & 98 (33.1) & 296 & \\
\hline Total & $236(66.3)$ & $120(33.7)$ & 356 & \\
\hline
\end{tabular}

\section{Discussion}

The moment a major congenital anomaly is diagnosed prenatally, the woman is left with two options, whether to terminate or continue with the pregnancy. [7] This is usually a difficult period in the life of a family whose joy of expecting a baby is short-lived by the knowledge of the baby having abnormalities. When a woman opts for termination of a pregnancy with a major anomaly, it is usually because the baby's life is at risk, not because the pregnancy is unwanted. [14] This explains the recommendation that, in cases of foetal abnormality incompatible with life, termination of the pregnancy should not be classified as induced abortion, medically or legally, but rather as a therapeutic premature delivery. Consequently, it would not be included within the scope of the legal restrictions on abortion. [14]
The findings from the present study show that $66.3 \%$ of the women interviewed agreed with the termination of pregnancies with major congenital anomalies. This was a little bit lower than what was recorded in a similar study by Souka et al. [15] where $83.4 \%$ of the women interviewed were willing to terminate pregnancies with lethal foetal anomalies. The reason for this high percentage might be because the women recruited into that study had not yet experienced such pregnancy.

The emotional attachment between a pregnant woman and her foetus is established during pregnancy, especially when the woman perceives the foetal movements. [8] This attachment makes a woman desire to continue with the pregnancy despite the knowledge of the presence of a major anomaly. 
Table II: Responses given by the participants who agreed with the termination of pregnancies with major anomalies.

\begin{tabular}{lll}
\hline Responses & Frequency & Percentage \\
\hline To prevent my child from suffering & 60 & 25.4 \\
I do not want to waste resources & 20 & 8.5 \\
I do not want to have an abnormal baby & 14 & 5.9 \\
To prevent recurrent hospital visits & 14 & 5.9 \\
Caring for an abnormal baby is tasking & 10 & 4.2 \\
To save time and prepare for the next pregnancy & 10 & 4.2 \\
To have rest of mind & 6 & 2.5 \\
If it is medical advice & 6 & 2.5 \\
I do not want to live in agony & 4 & 1.7 \\
To have time to take care of other children & 4 & 1.7 \\
I do not want a repeat of previous experience & 4 & 1.7 \\
The child will be useless to me & 4 & 1.7 \\
To prevent future depression in my baby & 3 & 1.3 \\
To be on the safe side & 3 & 1.3 \\
Since it cannot be treated and there is a way out & 2 & 0.9 \\
I cannot face the trauma of losing my child later & 2 & 0.9 \\
Other responses (1 each) & 44 & 18.6 \\
No response & 26 & 11.0 \\
Total & 236 & 100.0 \\
\hline
\end{tabular}

Table III: Responses given by the participants who disagreed with the termination of pregnancies with major anomalies.

\begin{tabular}{lll}
\hline Responses & Frequency & Percentage \\
\hline I trust God for a miracle & 56 & 46.7 \\
I will be committing murder & 16 & 13.3 \\
All children have the right to live & 10 & 8.3 \\
God will not allow it & 8 & 6.7 \\
I will live with regret & 8 & 6.7 \\
It is against my religion & 6 & 5.0 \\
Every child is a gift from God & 5 & 4.2 \\
The child might survive & 4 & 3.3 \\
I will be too attached to the baby & 4 & 3.3 \\
It is a sin & 3 & 2.5 \\
Total & 120 & 100 \\
\hline
\end{tabular}

Studies by Breeze et al. [16] and Gammeloft et al. [17] on women with foetuses with major congenital anomalies showed that $60 \%$ and $57 \%$ of the women respectively opted for the termination of pregnancy after being counselled on the severity of the anomalies. The proportion was even lower in a study conducted by Ndjapa-Ndamkou et al. [18] in South Africa, where women with lethal congenital anomalies were counselled on the severity of the congenital anomalies and the options available to them but only $33 \%$ of the women opted for termination of the pregnancy. This was in a country where termination of pregnancy is allowed at any gestation, once there is a consensus between at least two medical professionals that the foetus is going to be severely handicapped.

Some factors are thought to significantly influence the decision of women when faced with a pregnancy with a lethal anomaly. These 
include the religious beliefs, age of the patient, parity and education. In the present study, there was no statistically significant association between the socio-demographic characteristics and their choices of agreement or disagreement with the termination of pregnancies with a major anomaly. In the study by Souka et al., [15] the only two statistically significant factors that influenced the maternal decision on pregnancy termination were religious beliefs and the frequency of practising religious duties.

Ndjapa-Ndamkou et al., ${ }^{[18]}$ in their study found that women who opted to continue their pregnancies were significantly younger compared to those who decided to terminate the pregnancies. Also, there were more Christians who opted to continue with the pregnancies. A study by Al Sulaiman et al. [19] on the attitude on Saudi Arabia and UK Pakistani women to termination of pregnancies showed that cultural background could also be a significant factor in the willingness of women to terminate pregnancies with congenital anomalies. In that study, Saudi women were more favourably disposed to termination of pregnancy when compared with the UK Pakistani women. This effect of the cultural background was, however, not tested in this study.

Various reasons were provided by the women who agreed with the termination of pregnancies with major congenital anomalies and the most recurrent of the reasons were; they did not want to bring to life a child that will suffer and that they did not want to waste resources on an abnormal child. Other reasons were that they felt it was going to be too stressful on them and that terminating the pregnancy will give them time to prepare for another one. These responses are similar to those provided by the women who opted for termination of pregnancy in the study reported by Ndjapa-Ndamkou et al. [18] On the contrary, most of the women had no plan of getting pregnant in the next five years. In a study conducted by Da costa et al. [14] in Brazil, most of the women, that terminated pregnancies of foetuses with anomalies not compatible with life, did so because of the risk to both their health and those of the foetuses. After the termination of pregnancies, many of the women said that they still cried a lot, felt guilty, sad and vulnerable. They claimed that they had a very hurting experience because they had lost a child. However, they all believed that the decision to terminate the pregnancy was the best and they had no regrets. Govender et al. [20] and Salvesen et al. [21] suggested that choosing to terminate a pregnancy with major anomalies may have long term psychological sequelae, in particular, a feeling of guilt at having caused the death of the baby.

The choice of a woman to continue with the pregnancy of a foetus with a major anomaly is a very difficult one because it poses a challenge to the healthcare professionals who need to prepare the woman psychologically for the experience she will face after delivery. Also, the professionals involved will have to be prepared for the management of the baby after delivery by involving all the other multidisciplinary professionals that might assist in the management. [22,23]

In the study by Ndjapa-Ndamkou et al., [18] the common reasons given by women for continuing with the pregnancies with major anomalies included: fear of killing an unborn baby, that a baby is God's gift and the baby will be well after it is born, that nature should be allowed to take its course, and that there should be no interference with the pregnancy. Similar reasons were given in the present study and also, many of them said that they trusted God for a miracle while some said they will be guilty of murder. Of the women that continued with the pregnancy in the study by Ndjapa-Ndamkou et al., ${ }^{[18]}$ two regretted their decisions after delivery when they saw the malformed babies and they had to consult with social workers before discharge from the 
hospital. This infers that any woman with a prenatally diagnosed foetus with congenital anomalies should have access to adequate counselling so that she can be aware of the consequences of the decisions she makes.

\section{Conclusion}

The findings from this study show that majority of the women were favourably disposed to termination of pregnancies with major anomalies. However, proper counselling has to be given any woman with such pregnancies to be aware of the consequences of the decisions they make. Also, in a country like Nigeria where there is a restricted abortion law, efforts should be made to factor in the termination of pregnancies with major anomalies into the abortion law.

Authors' Contributions: EEJ conceived the study and participated in data collection. AJA participated in data collection, data analysis and drafting of the manuscript. Both authors reviewed the draft and approved the final version of the manuscript.

Conflict of Interest: None declared.

Funding: Self-funded.

Publication History: Submitted 05 July 2020; Accepted 04 August 2020.

\section{References}

1. Mathers CD, Loncar D. Projections of global mortality and burden of disease from 2002 to 2030. PLoS Med 2006; 3: e442.

2. ICBDMS. Congenital Malformations Worldwide. A Report from the International Clearinghouse for Birth Defects Monitoring Systems, Rome, Italy, 2010. Accessed 16 October 2019.

3. World Health Statistics. World Health Organization, Geneva; 2008. EB 125/7.

4. Christianson A, Howson CP, Modell B. March of Dimes: Global Report on Birth Defects - The Hidden Toll of Dying and
Disabled Children March of Dimes Birth Defects Foundation. White Plains, NY. 2006.

5. Mazer P, Gischler S, Koot H, Tibboel D, Dijk M, Duivenvoorden $H$. Impact of a child with congenital anomalies on parents (ICCAP) questionnaire; a psychometric analysis. Health Quality Life Outcomes 2008; 6: 102-112.

6. Levi S. Ultrasound in prenatal diagnosis: polemics around routine ultrasound screening for second-trimester fetal malformations. Prenat Diagn 2002; 22: 285295.

7. Rauch ER, Smulian JC, DePrince K, Ananth CV, Marcella SW. Pregnancy interruption after second-trimester diagnosis of fetal structural anomalies: The New Jersey Fetal Abnormalities Registry. Am J Obstet Gynecol. 2005; 193:1492-1497.

8. Gesser-Edelsburg A, Shahbari NA. Decision-making on terminating a pregnancy for Muslim Arab women pregnant with fetuses with congenital anomalies: maternal affect and doctorpatient communication. Reproductive Health. 2017; 14: 49.

9. Royal College of Obstetricians and Gynaecologists. Termination of Pregnancy for Fetal Abnormality in England, Wales and Scotland. Working Party Report. London: RCOG; 1996.

10. Finer L, Fine JB. Abortion law around the world: progress and pushback. Am J Public Health 2013; 103: 585-589.

11. Choice of Termination of Pregnancy Amendment Act, 2004. South African Government Gazette 2005; 476: 27267.

12. World Abortion Policies.2007. Accessed at http://www.un.org/esa/population/pub lication/ 2007 abortion_policies_chart. Accessed 20 April 2019.

13. Akinmoladun JA, Ogbole GI, Oluwasola TAO. Pattern and outcome of prenatally diagnosed major congenital anomalies at a 
Nigerian Tertiary Hospital. Niger J Clin Pract Practice 2018; 21: 560-565.

14. Ferreira da Costa LL, Hardy E, Duarte Osis MR, Faundes A. Termination of Pregnancy for Fetal Abnormality Incompatible with Life: Women's Experiences in Brazil. Reproductive Health Matters 2005; 13: 139-146.

15. Souka AP, Michalitsi VD, Skentou H, et al. Attitudes of pregnant women regarding termination of pregnancy for fetal abnormality. Prenat Diagn 2010; 30: 977980.

16. Breeze ACG, Lees CC, Kumar A, Missfelder-Lobos $\mathrm{HH}$, Murdoch EM. Palliative care for prenatally diagnosed lethal fetal abnormality. Arch Dis Child Fetal Neonatal Ed 2007; 92: F56-F58.

17. Gammeltoft T, Hang TM, Hiep NT, Hanh NTT. Late-term abortion for fetal anomaly: Vietnamese women's experience. Reprod Health Matters 2008; 16: 46-56.

18. Ndjapa-Ndamkou C, Govender L, Moodley J. Views and attitudes of pregnant women regarding late termination of pregnancy for severe fetal abnormalities at a tertiary hospital in KwaZulu-Natal. South Afr J Obstet Gynaecol 2013; 19: 49-52.
19. Al-Sulaiman A, Hewison J. Abu-Amero KK, Ahmed S, Green JM, Hirst J. Attitudes to prenatal diagnosis and termination of pregnancy for 30 conditions among women in Saudi Arabia and the UK. Prenatal Diagnosis 2012; 32: 1109-1113.

20. Govender L, Ndjapa-Ndamkou C, Aldous C, Moodley J. A pilot study of women's experiences after being offered late termination of pregnancy for severe fetal anomaly. Niger J Clin Pract 2015; 18 (Suppl 1): S71-S76.

21. Salvesen KA, Oyen L, Schmidt N, Malt UF, Eik-Nes $\mathrm{SH}$. Comparison of long-term psychological responses of women after pregnancy termination due to fetal anomalies and after perinatal loss. Ultrasound Obstet Gynecol 1997; 9: 80-85.

22. Crombleholme TM, D'Alton M, Cendron M, Alman B, Goldberg MD, Klauber GT, et al. Prenatal diagnosis and the pediatric surgeon: the impact of prenatal consultation on perinatal management. J Pediatr Surg 1996; 31:156-162.

23. Luks FI, Carr SR, Feit LR, Rubin LP. Experience with a multidisciplinary antenatal diagnosis and management model in fetal medicine. J Matern Fetal Neonatal Med 2003; 14: 333-337. 